\title{
The General Meeting of the Russian Academy of Sciences
}

DOI: $10.1134 / \mathrm{S} 1019331611050091$

\author{
Address of Academician V. N. Charushin
}

Let me draw the attention of the participants in the meeting to the necessity to improve organizational work in a number of areas.

Today, more than ever, we should form a positive image of the Russian Academy of Sciences; the participation of academic institutes in the implementation of national-level projects may contribute to this. As is known, there are dozens of enterprises of the State Atomic Energy Corporation (Rosatom), the Russian Federal Space Agency (Roscosmos), Gazprom, and machine-building and aircraft-engineering complexes. Recently, many of these high-tech enterprises have increasingly been interested in interaction with academic science, which is quite understandable under the shortage of industrial institutes. In particular, last year, the RAS Ural Branch signed more than 20 agreements with the largest Ural enterprises, such as the State Rocket Center, the Semikhatov NPO Avtomatiki, the Novator Design Bureau, the Perm Instrument-Making Company, the Uralvagonzavod Research and Production Corporation, the Iskra Research and Production Association, the VSMPO Corporation, known today as the base of the Titanium Valley project, the Perm Engine Company Aviadvigatel', and many others.

Quite recently, a meeting of the Presidium of the RAS Ural Branch discussed interaction with aircraft builders, and the leader of the Aviadvigatel' Company A.A. Inozemtsev called the academic community for participation in solving a large number of problems associated with the development of basic studies in the field of aircraft engines. Similar processes are taking place in the RAS Siberian, Far East, and Central Branches. In his report, Academician V.V. Kostyuk named the largest corporations with which the Academy of Sciences had signed agreements. It is time to coordinate activities in this field and to join efforts of the RAS regional branches and research centers within the framework of large-scale projects.

All of us successfully passed the pilot project, and it brought a new level of remuneration to academic institutes. At the same time, however, the implementation of this project led to an expenditure structure that is far from being optimal. The regional branches acutely feel an urgent need for overhauling and reconstruction of academic buildings and for the creation of a modern technological and engineering infrastructure. Without solving these problems, we will not be able to lay claim to a modern level of studies, especially in the international arena. The point is that, when the regional branches or regional centers try to obtain something from the targeted investment program of the Russian Ministry of Economic Development single-handedly, their efforts are often in vain. The Academy must have a perspective plan of reconstruction and modernization that would cover all the branches.

In conclusion, let me mention the problem of international collaboration. A characteristic feature of this year is that the regional branches, particularly the Ural Branch, have no funds to receive foreign scientists despite the existing long-standing connections. I mean contacts with hundreds of foreign scientists. Previously, such receptions were centralized, at the expense of our international department; today, our branch has to find external sources, and, naturally, the burden falls onto academic institutes. If our approach to international collaboration is serious, we should have a departmental target program and respective budgeting. Overall, it is inadmissible when the country announces a tender for the creation of international scientific laboratories but only institutions of higher education can participate in it, while academic institutes are excluded from it. As a result, the developed connections, collaboration, and integration are undermined.

In 2011, Yekaterinburg became the "launching pad" for a new international project aimed at interacting with European countries. In our opinion, the Era.net.rus program is sufficiently attractive, but, at the same time, its implementation is possible only if additional funds are allocated. This is a situation in which the Academy could ask the Ministry of Education and Science and the Russian government for financial support for this program, which would stimulate the development of international collaboration with both academic institutes and establishments of higher education. 